\title{
The Effect of the Elderly's Motivation to Participate in Lifelong Education on their Life Satisfaction
}

\author{
Kang Won Cho1), Chong Sok Choe')
}

\begin{abstract}
The purpose of this study is to research the effect of the elderly's motivation to participate in lifelong education on their life satisfaction. Data was collected from November 1, 2018 to December 31, 2018. The survey was distributed to 250 elderly living in $\mathrm{K}$ city and a total of 209 responses were used in the final data analysis. As a result, activity-oriented motivation $(\beta=.448 \mathrm{p}<.001)$ was found to have the greatest influence in regards to the effect of the elderly's lifelong education motivation on life satisfaction. The explanatory power of this model was 35.3\%. Such results show the importance of increasing activity-oriented motivation in the elderly to improve life satisfaction of those participating in lifelong education. The increase in life expectancy and various social changes necessitate lifelong education of the elderly. In the case of the elderly, lifelong education programs provide an opportunity to improve the quality of life by overcoming social alienation and promoting interpersonal relationships. Hence, activity-oriented motivation can be construed to be effective in improving the life satisfaction of the elderly.
\end{abstract}

Keywords: Elderly, Lifelong Education, Life, Satisfaction, Motivation

\section{Introduction}

It is projected that Korea will surpass $20.8 \%$ by 2026 and become a super-aged society. Such a rapid increase in the aging population can be considered to be caused by developments in science and technology and changes in our standard of living. With an increasing life expectancy, there is increasing interest in the life satisfaction of the elderly. A wide range of studies has been conducted in order to improve the lives of the elderly and effectively react to the aging population[1-4]. As such, research on the elderly's life satisfaction and interest in this topic are essential; it is not an individual-level issue but must be dealt with by the family and

Received(April 1, 2019), Review Result(1st: April 22, 2019, 2nd: May 28, 2019), Accepted(June 10, 2019)

1) (Doctorate Student) 32906 Dept. of Buddhist, Geumgang Univ., 522, Sangwol-ro, Sangwol-myeon, Nonsan-si, Chungcheongnam-do, Republic of Korea

email: sws423@daum.net

2) (An Emeritus Professor, Corresponding Author) 32906 Dept. of Buddhist Culture, Geumgang Univ., 522, Sangwol-ro, Sangwol-myeon, Nonsan-si, Chungcheongnam-do, Republic of Korea email: chsch@ggu.ac.kr 
local community as well as the government. High life satisfaction is an indicator of how happy and successful old age is so it must be given attention[5].

Lifelong education of the elderly is rising to become an important alternative to solving problems of the elderly. An increase in an individual's life expectancy means a protraction of one's time spent as an old person. How one spends one's prolonged lifetime is very important because it determines the quality of life in the later years of one's life. Therefore, creative thinking, along with active intervention in lifelong education for the elderly, is needed to create a meaningful old age and the importance of lifelong education for the elderly. [6] is becoming all the more emphasized.

[7] is lifelong education for the elderly that focuses on materializing conditions that enable the elderly to exhibit their potential as much as possible through the increase in knowledge, training, and maturity through continuous education. Elderly education is a part of lifelong education that happens over the course of one's entire lifetime that improves the quality of life in regards to all areas of culture[8]. reveals that the importance of elderly education as a method of enabling the elderly to age successfully is being emphasized, while lifelong education for all ages is becoming greatly important with the advent of a knowledge-based society. It emphasizes that besides the unique goal of delivering new knowledge, lifelong education is an effective method of providing the elderly with the educational opportunity that will ultimately solve problems such as solitude, alienation, and loneliness in the elderly population. Moreover, the elderly showed to have higher life satisfaction after participating in elderly education[9], while elderly who participated in elderly education showed to have higher life satisfaction or morale than those that did not[10].

In order for humans to live on as autonomous beings, unending self-growth and self-realization are mandatory, which is also the process of improving life satisfaction - hence, the quality of life. The self-realization process necessitates continuous lifelong education which, in turn, is necessary also from the perspective of vocational resocialization education and utilziing elderly human resources as it enables the elderly to lead a happy old age[11]. Furthermore, studies such as [12] claim that lifelong education for the elderly plays a crucial role of enabling them to acquire knowledge, decrease the sense of alienation and solitude, grow an ability to adapt to lead a meaningful life, and acquire a motivation and attitude to become independent. Therefore, lifelong education for the elderly helps improve life satisfaction, decreases depression, and increases self-efficacy by strengthening positivity in life which then improves their quality of life and enables them to age successfully.

Lifelong education for the elderly provides diverse programs for each topic that helps them 
lead a healthy old age. By doing so, the elderly are able to adapt quickly to an ever-changing modern society and replaces the boredom of retired life with joy and a sense of accomplishment. Therefore, lifelong education for the elderly is undoubtedly contributing to the improvement of their quality of life.

Through this study, we will be able to acquire baseline data on lifelong education programs for the elderly and understand their relationship with life satisfaction of the elderly. It will be able to be utilized as baseline data to help achieve a successful aging process. Thus, this study attempted to verify whether the elderly's motivation to participate in lifelong education had an effect on their life satisfaction. The following are the research questions:

1. What was the level of motivation to participate in lifelong education and life satisfaction as perceived by the elderly?

2. What are the effects of motivation to participate in lifelong education as perceived by the elderly on life satisfaction?

\section{Research Method}

\subsection{Research Questions}

Data was collected from November 1, 2018 to December 31, 2018. The survey was distributed to 209 elderly 65 years of age or older living in K city. The survey was in the form of a self-administered questionnaire which was conducted after sufficient directions on its aim and method of composition were given.

\subsection{Research Tools}

\subsubsection{Sociological Characteristics of the Population}

Content related to sociological characteristics of the population comprised age, education level, economic status, etc.

\subsubsection{Motivation to Participate in Lifelong Education}

The scale for motivation to participate used in this study to measure the elderly's motivation to participate in lifelong education was developed by [13]. and utilized in [14]. This scale is composed of a total of 15 questions, of which 5 measure activity-oriented motivation, 5 
measure goal-oriented motivation, and 5 measure study-oriented motivation. The Likert scale which offers a choice of 5 points was utilized as the response format - 5 meaning 'strongly agree' and 1 meaning 'strongly disagree'. Thus, the higher the score, the higher the motivation to participate. Reliability of the motivation to participate shown in [14]. showed to be a Cronbach's alpha of .733 for activity-oriented motivation, .822 for goal-oriented motivation, and .829 for study-oriented motivation. The total reliability of this study was a Cronbach's alpha of .924, while it was .876 for activity-oriented motivation, .839 for goal-oriented motivation, and .877 for study-oriented motivation.

\subsubsection{Life Satisfaction}

The scale for life satisfaction developed by [15]. and utilized by [16]. was utilized in order to measure the elderly's life satisfaction. Life satisfaction comprises of a total of 3 questions. The response for each question used the Likert scale which offers a choice of 5 points was utilized as the response format - 5 meaning 'strongly agree' and 1 meaning 'strongly disagree'. Thus, the higher the score, the higher the life satisfaction. The reliability of the motivation to participate and life satisfaction was verified to be valid. In [16], there was a Cronbach's alpha of .737 while this study's reliability was a Cronbach's alpha of .680 .

\subsection{Data Processing and Analysis Method}

The SPSS 18.0 program was utilized to process the collected data for this study and was verified with a $5 \%$ significance level. The reliability of each research tool was measured by the Cronbach's alpha while the study subjects' sociological characteristics of the population and major variables were measured by conducting a frequency analysis and descriptive statistics to find a percentage, average, and standard deviation. A correlation analysis was carried out to find the correlation between major variables, while a hierarchical regression analysis was carried out in order to find the effects of dependent variables on happiness.

\section{Study Results}

\subsection{Sociological Characteristics of the Population}

The results of studying the sociological characteristics of the population of the elderly who were subjects of this study are shown in [Table 1] below. 
When observing their sociological characteristics of the population, ages $65 \sim 70$ had the highest ratio at $70.0 \%$ (147 people), while $85.2 \%$ (178 people) were females. The level of education was observed to be $39.2 \%$ (78 people) middle school graduates, $12.0 \%$ (25 people) elementary school graduates, and 7.7\% (16 people) university graduates.

[Table 1] The Demographic Characteristics of Subjects ( $\mathrm{N}=209)$

\begin{tabular}{|c|c|c|c|}
\hline \multicolumn{2}{|c|}{ Category } & Frequency & Percentage \\
\hline \multirow{4}{*}{ Age } & $65 \sim 70$ & 147 & 70.3 \\
\cline { 2 - 4 } & $70 \sim 75$ & 38 & 18.2 \\
\cline { 2 - 4 } & $75 \sim 80$ & 20 & 9.6 \\
\hline \multirow{3}{*}{ Education level } & $80 \sim 90$ & 4 & 1.9 \\
\cline { 2 - 4 } & Less than elementary school & 7 & 3.3 \\
\cline { 2 - 4 } & Graduated elementary school & 25 & 12.0 \\
\cline { 2 - 4 } & Graduated middle school & 78 & 37.3 \\
\cline { 2 - 4 } & Graduated high school & 82 & 39.2 \\
\cline { 2 - 4 } & Graduated university & 16 & 7.7 \\
\hline \multirow{3}{*}{ Economic status } & Graduated graduate school & 1 & .5 \\
\cline { 2 - 4 } & Normal & 193 & 92.3 \\
\hline
\end{tabular}

\subsection{Motivation to Participate in Lifelong Education, Life Satisfaction}

In order to verify the motivation to participate in lifelong education and life satisfaction, descriptive statistics were analyzed as shown in [Table 2] below.

[Table 2] Technical Statistics on Key Variables ( $N=209)$

\begin{tabular}{|c|c|c|c|c|c|}
\hline \multicolumn{2}{|c|}{ Category } & Minimum value & Maximum value & Average & Standard deviation \\
\hline \multirow{3}{*}{$\begin{array}{l}\text { Motivation } \\
\text { to } \\
\text { participate }\end{array}$} & $\begin{array}{c}\text { Goal-oriented } \\
\text { motivation }\end{array}$ & 4.00 & 16.00 & 10.268 & 2.672 \\
\hline & $\begin{array}{c}\text { Activity-oriented } \\
\text { motivation }\end{array}$ & 5.00 & 20.00 & 12.531 & 2.995 \\
\hline & $\begin{array}{c}\text { Study-oriented } \\
\text { motivation }\end{array}$ & 3.00 & 12.00 & 7.450 & 2.119 \\
\hline \multicolumn{2}{|c|}{ Life satisfaction } & 3.00 & 10.00 & 7.077 & 1.699 \\
\hline
\end{tabular}


Results of analyzing descriptive statistics to find the level of study subjects showed that when measurement variables were analyzed with descriptive statistics, goal-oriented motivation was $M=10.268$, activity-oriented motivation was $M=12.531$, and study-oriented motivation was $\mathrm{M}=7.450$. Life satisfaction was $\mathrm{M}=7.077$.

\subsection{Correlation between Motivation to Participate in Lifelong Education and Life Satisfaction}

In order to verify the correlation between study subjects' motivation to participate in lifelong education and life satisfaction, the Pearson correlation coefficient was found, the results of which are shown in [Table 3] below.

[Table 3] Correlation between Motivation to Participate in Lifelong Education and Life Satisfaction ( $N=209)$

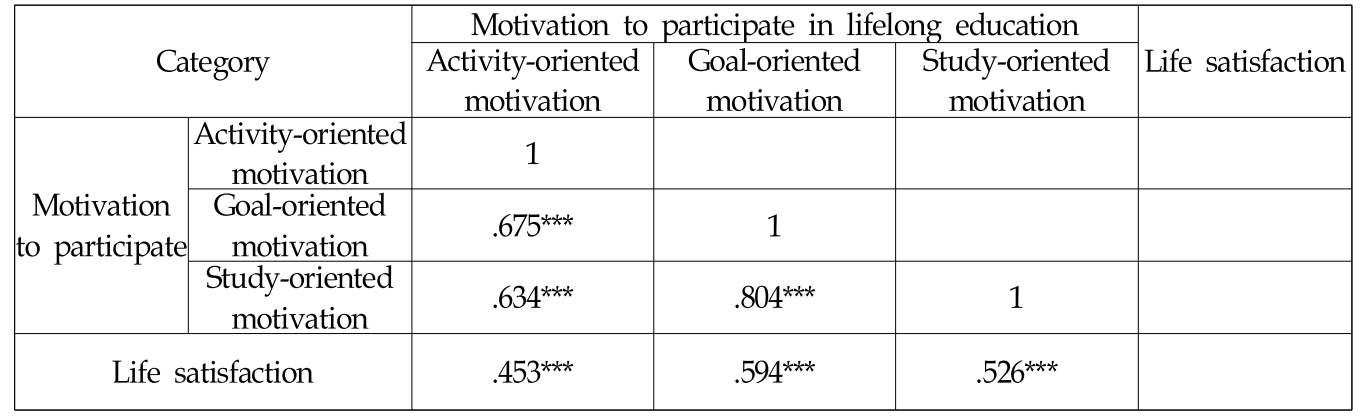

${ }^{* * \mathrm{P}}<.01$

Results revealed that measurement variables have a positive correlation, with activity-oriented motivation at $\mathrm{r}=.453$, goal-oriented motivation at $\mathrm{r}=.594$, and study-oriented motivation at $\mathrm{r}=.526$, showing statistical significance $(p<0.001)$. This signifies that the higher the elderly's motivation to participate in lifelong education, the higher their life satisfaction.

\subsection{Effects of Motivation to Participate in Lifelong Education on Life Satisfaction}

The results of a hierarchical regression analysis conducted to find the effects of study subjects' motivation to participate in lifelong education on life satisfaction are shown in [Table 4] below. 
[Table 4] An Analysis of Motivation to Participate in Lifelong Education on Life Satisfaction (N=209)

\begin{tabular}{|c|c|c|c|c|c|}
\hline \multirow{2}{*}{\multicolumn{2}{|c|}{ Independent variables }} & \multicolumn{4}{|c|}{ Model 1} \\
\hline & & B & S.E & $\beta$ & $\mathrm{t}$ value \\
\hline \multicolumn{2}{|r|}{ (Invariable) } & 2.694 & .428 & & $6.292^{* * *}$ \\
\hline \multirow{3}{*}{$\begin{array}{l}\text { Motivation } \\
\text { to } \\
\text { participate }\end{array}$} & Activity-oriented motivation & .254 & .057 & .448 & $4.454^{* * *}$ \\
\hline & Goal-oriented motivation & .048 & .049 & .076 & .979 \\
\hline & Study-oriented motivation & .095 & .077 & .118 & 1.230 \\
\hline \multicolumn{2}{|r|}{$\mathrm{R}^{2}$} & \multicolumn{4}{|c|}{.362} \\
\hline \multicolumn{2}{|r|}{$\triangle \mathrm{R}^{2}$} & \multicolumn{4}{|c|}{.353} \\
\hline & $\mathrm{F}(\mathrm{df1} / \mathrm{df} 2)$ & \multicolumn{4}{|c|}{$38.755^{* * *}$} \\
\hline
\end{tabular}

The results of analyzing the influencing factors of the elderly's motivation to participate in lifelong education on life satisfaction are shown in [Table 4]. A regression analysis on the elderly's motivation to participate in lifelong education and life satisfaction showed that activity-oriented motivation $(\beta=.448 \mathrm{p}<.001)$ had a statistically significant effect $(\mathrm{p}<.001)$. When comparing the standardized regression coefficient, activity-oriented motivation had the biggest influence. This regression model $(\mathrm{F}=38.755, \mathrm{p}<.001)$ showed statistically significant results, while the model's explanatory power's $\mathrm{R}^{2}$ statistic was .35 .3 which revealed that it affected life satisfaction at approximately $35.3 \%$.

\section{Conclusion and Suggestions}

This study verified the effects of the elderly's motivation to participate in lifelong education on their life satisfaction in order to provide baseline data for improving the elderly's life satisfaction. Data was collected from November 1, 2018 to December 31, 2018. The survey was distributed to 209 elderly 65 years of age or older living in K city. The survey was in the form of a self-administered questionnaire which was conducted after sufficient directions on its aim and method of composition were given. The SPSS 18.0 program was utilized to process the collected data for this study and was verified with a $5 \%$ significance level. The reliability of each research tool was measured by the Cronbach's alpha while the study subjects' sociological characteristics of the population and major variables were measured by conducting a frequency analysis and descriptive statistics to find a percentage, average, and standard deviation. A correlation analysis was carried out to find the correlation between major variables, while a hierarchical regression analysis was carried out in order to find the effects of dependent variables on happiness. 
Study results showed that firstly, goal-oriented motivation was $M=10.268$, activity-oriented motivation was $M=12.531$, and study-oriented motivation was $M=7.450$. Life satisfaction was $\mathrm{M}=7.077$. Secondly, motivation to participate in lifelong education had a positive correlation with life satisfaction. Thirdly, from verifying the effects of the elderly's motivation to participate in lifelong education, it was observed that activity-oriented motivation had the biggest influence $(\beta=.448 \mathrm{p}<.001)$. This model's explanatory power was $35.3 \%$. Such results reveal that it is important to increase the activity-oriented motivation of elderly participants of lifelong education in order to improve their life satisfaction. This is similar to the study results shown in [13]. The increase in life expectancy and societal changes necessitate the elderly's lifelong education. In the case of the elderly population, participating in lifelong education helps them improve interpersonal relationships and overcome alienation, hence improving their quality of life. It can be construed that activity-oriented motivation is effective in improving the elderly's life satisfaction.

\section{References}

[1] J. H. Kim, Study on the Feelings of Depression, Adaptation to Society, Satisfaction with Leisure, and Satisfaction with Living, Basing on Old Persons' Participation Traits in Leisure, Doctorate in Department of Physical Education Graduate School of Chonnam National University, (2013)

[2] B. I. Choi, Effects of Community Resources on Life Satisfaction: A Multilevel Anlaysis of Older People, Dept. of Child and Family Studies The Graduate School Yonsei University, (2017)

[3] S. Y. Kim, The Effect of Daily Stress and Social Support on Aged People's Life Satisfaction, Dongshin University Graduate School Development Counseling Psychology, (2016)

[4] Y. J. Choi, The Impact Subjective Class Consciousness on Life Satisfaction of the Elderly: A Mediation Effect of Depression, Journal of the Korea Academia-Industrial cooperation Society, (2018), Vol.19, No.6, pp.209-218.

[5] S. E. Kim, E. J. Lee and S. D. Jeong, Analysis of Life Satisfaction of the Elderly Using Multilayer Model, Korea Geriatrics, (2016), Vol.18, No.3, pp.581-594.

[6] J. R. Han, Education for the elderly, Hajasa, (2006)

[7] Wilhelmsen. L, Lung mechanics in rheumatic valvular disease, Acta medica Scandinavica, Supplementum, (1968), Vol.489, No.3, pp.3-114.

[8] J. Y. Kim and J, M, Lee, The Effect of Elderly Education on Life Satisfaction, Welfare for the Elderly, (2010), Vol.48, pp.7-29.

[9] K. W. Joe, A Case Study on Elderly Education, Social Relations, and Life Satisfaction Welfare for the 
Elderly, (2006), Vol.23, pp.127-156.

[10] J. H. Lee and W. Kim, A Study about the Effects of Education for the Elderly on their Psychological Well-Being, Korea Geriatrics, (2008), Vol.28, No.4, pp.887-905.

[11] E. J. Kyun and S. O. Lee, Pyeongsaeng-gyoyug: Ilonpyeon, Gyoyuggwahagsa, (2001)

[12] H. G. Shin and S. J. Lee, Factors Influencing on the Length of Time When the Subjective and Economic Poverty Occurs to the Elderly after Retirement, Welfare for the Elderly, (2013), Vol.71, No.4, pp.61-89.

[13] C. O. Houle, The inquiring mind. Oklahoma Research Center for Continuing Professional and Higher Education, University of Oklahoma, (1961)

[14] J. S. Kim, Y. G. Rim, An Impact on the Relationship among Elderly's Motivation to Participate in Lifelong Education, Educational Satisfaction and Life Satisfaction, Journal of the Korea Contents Association, (2014), Vol.14, No.5, pp.179-189.

[15] S. J. Choe, A Study on the Development of Life Satisfaction Scale for the Elderly, Ewha Women University, Korean Cultural Institute, (1986), Vol.49, pp.233-256.

[16] J. S. Kim, A Study on the Relationship between the Elderly's Motivations for Participating in Lifelong Education and the Level of their Educational Satisfaction as well as the Quality of Life: With a Focus on the Moderating Effects of Religious Life, Department of Elderly Welfare, Doctorate in the Gradute School of Venture Hoseo University, (2015) 